\title{
Water volume differentially modifies copepod predatory strengths on two prey types
}

Article

Accepted Version

Cuthbert, R. N., Sithagu, R., Weyl, O. L. F., Wasserman, R. J., Dick, J. T. A., Callaghan, A., Froneman, P. W., Foord, S. and Dalu, T. (2020) Water volume differentially modifies copepod predatory strengths on two prey types. Limnologica, 81. 125747. ISSN 0075-9511 doi: https://doi.org/10.1016/j.limno.2020.125747 Available at https://centaur.reading.ac.uk/88541/

It is advisable to refer to the publisher's version if you intend to cite from the work. See Guidance on citing.

To link to this article DOI: http://dx.doi.org/10.1016/j.limno.2020.125747

Publisher: Elsevier

All outputs in CentAUR are protected by Intellectual Property Rights law, including copyright law. Copyright and IPR is retained by the creators or other copyright holders. Terms and conditions for use of this material are defined in the End User Agreement. 


\section{CentAUR}

Central Archive at the University of Reading

Reading's research outputs online 
2 Water volume differentially modifies copepod predatory strengths on two prey types

3 Ross N. Cuthbert ${ }^{1,2,3, *}$, Rotondwa Sithagu ${ }^{4}$, Olaf L. F. Weyl ${ }^{3}$, Ryan J. Wasserman ${ }^{5}$, Jaimie

4 T. A. Dick ${ }^{1}$, Amanda Callaghan ${ }^{2}$, P. William Froneman ${ }^{6}$, Stefan Foord $^{4}$, Tatenda Dalu ${ }^{4}$

$6{ }^{1}$ Institute for Global Food Security, School of Biological Sciences, Queen's University Belfast, 7 Belfast BT9 5DL, Northern Ireland

$8{ }^{2}$ Ecology and Evolutionary Biology, School of Biological Sciences, University of Reading,

$9 \quad$ Reading RG6 6AS, England

$10{ }^{3}$ DST/NRF Research Chair in Inland Fisheries and Freshwater Ecology, South African

Institute for Aquatic Biodiversity, Makhanda 6140, South Africa

12

13

14

15

16

17

18

19

20

${ }^{4}$ Department of Ecology and Resource Management, University of Venda, Thohoyandou 0950,

South Africa

${ }^{5}$ Department of Biological Sciences and Biotechnology, Botswana International University of Science and Technology, Palapye, Botswana

${ }^{6}$ Department of Zoology and Entomology, Rhodes University, Makhanda 6140, South Africa

*Corresponding author: rossnoelcuthbert@gmail.com 


\section{Abstract}

23 Predatory interaction strengths are highly context-dependent, and in temporary aquatic

24 ecosystems, may be affected by water volume changes. We examine the influence of water

25 volume on Lovenula raynerae (Copepoda) functional responses towards two temporary pond prey types. Daphnia prey risk was not affected by increasing water volume, whereas for

27 Culex prey risk was reduced. Accordingly, water volume changes through the hydroperiod may have species-specific effects on prey, with implications for population persistence under environmental change.

\section{Keywords}

32 Search area; functional response; interaction strength; copepod; daphnid; culicid 
Determining factors which influence the strength of interactions between species is essential for understanding community-level stabilities and dynamics within ecosystems (McCann et al., 1998; Vázquez et al., 2015). Context-dependencies can modify prey risk from predators in heterogeneous environments and can be measured experimentally to help predict population persistence (Dick et al., 2014). Search area may be a particularly important context-dependency that influences the strength of trophic interactions through, for example, alterations to prey encounter and clearance rates (Uiterwaal and DeLong, 2018). In temporary pond ecosystems, water volume is highly changeable spatiotemporally owing to naturally periodic wet and dry states, potentially altering the nature of trophic dynamics therein. Such undulations in water volumes through the hydroperiod may be an important contributor to species extirpations and reported 'boom-bust' dynamics (Wasserman et al., 2018). The effect of water volume on trophic interactions among temporary pond specialist biota is, however, poorly understood. This limits understandings of the influence of predicted future droughts and land use changes for ecological functioning of these biodiverse systems (Dalu et al., 2017).

Prey risk is known to differ between species where they coexist within aquatic communities (Cuthbert et al., 2018). Differences in behavioural traits between prey species may modify the influence of context-dependencies on predation risk (Laverty et al., 2015). For pelagic predators and prey which occupy three-dimensional space throughout the water column, interaction strengths may be relatively unaffected by increasing search area than towards prey species which remain at the surface or benthos. Likewise, predators which forage in twodimensional space may be affected to a lesser extent by water volume change towards benthic or surficial prey compared to pelagic prey items. Accordingly, the influence of water volume 
change could differ between predator-prey participants and may alleviate or exacerbate predation risk depending on fundamental behavioural traits and spatial occupancies.

The present study uses a functional response approach to comparatively quantify the influence of water volume change for interaction strengths towards two temporary pond prey types. We consider functional responses comparatively as our results are not bolstered by empirical validation of parameters which could facilitate mechanistic interpretation (see Dick et al., 2014). Functional responses quantify resource use as a function of resource density and their shape and magnitude can be a useful indicator of prey population stability outcomes (Holling, 1959; Dick et al., 2014). Focusing on the pelagic temporary pond specialist copepod Lovenula raynerae as a predator, functional responses are quantified under five different water volumes towards two common prey types, Daphnia longispina (i.e. water flea) and Culex pipiens (i.e. mosquito larva). This predator is often numerically dominant in temporary ponds within the study area (Wasserman et al., 2018). In our predator-prey system, given that $D$. longispina is a pelagic species whilst $C$. pipiens is a surface-dweller, we expect interactions with the latter species to be more profoundly affected by the experimental water volume gradient.

Adult male L. raynerae ( $4.5-5.0 \mathrm{~mm}$ total length) were collected from a temporary pond close to Makhanda (Grahamstown) in the Eastern Cape Province of South Africa during April 2019 (33 $\left.15^{\circ} 02.6^{\prime \prime S} 26^{\circ} 26^{\prime} 13.1 " \mathrm{E}\right)$. Copepods were transported in source pond water to a controlled environment (CE) room at the Department of Zoology and Entomology, Rhodes University that was maintained at $25^{\circ} \mathrm{C}\left( \pm 1{ }^{\circ} \mathrm{C}\right)$ and under a 14 :10 light and dark photoperiod regime, corresponding with natural local conditions. Copepods were starved in 
91 filtered source water from the collection site for 24 hours prior to experimentation, to allow for gut clearance and standardisation of hunger levels.

93

94 Two prey types were collected and used in the experiment, D. longispina and C. pipiens. Daphnids (total length (excluding spine): $1.8-2.1 \mathrm{~mm}$ ) were collected from a reservoir adjacent to the copepod collection site $\left(33^{\circ} 15^{\prime} 04.2^{\prime \prime} \mathrm{S} 26^{\circ} 26^{\prime} 17.1^{\prime \prime E}\right)$. Culicids (total length: $2.0-3.0 \mathrm{~mm}$ ) were collected from container-style aquatic habitats on the university campus. Both prey types were housed in the same CE room as the copepod predators until experimentation.

Two separate feeding experiments were conducted according to prey type, given different feeding durations were required to reach asymptotic consumption rates towards each prey type. Five water volume treatments were applied to glass jars of $5.6 \mathrm{~cm}$ diameter $(20,40,60$, 80 and $100 \mathrm{~mL}$ ) using filtered source water from the copepod collection site (as before). Five supplies of each prey type were distributed among each water volume level $(2,4,8,16$ and 32 individuals arena ${ }^{-1}$; densities as per Table 1). The range of prey densities used in the present study reflects the abundances and high natural variability of biota within temporary wetland ecosystems (Wasserman et al., 2018), and a large range of prey densities is required to facilitate asymptotic declines in feeding rates in functional response experiments (see Dick et al., 2014). Each prey type was allowed to settle for one hour prior to the addition of individual copepod predators. After introduction, predators were allowed to feed on daphnids or culicids for 18 and 4 hours, respectively. Each treatment group was replicated four times for each prey type, and a further replicate of predator-free controls was run for each prey 
type, water volume and prey density (i.e., 2 prey $\times 5$ volumes $\times 5$ supplies $\times 4$ replicates + controls $=250$ experimental units overall).

Given differences in feeding times towards each prey type (see before), statistical analyses were conducted separately for daphnids and culicids. Poisson generalised linear models with $\log$ links were used to examine overall prey consumption as a function of water volume and prey supply, and their interaction. A dispersion test was used to confirm that residuals were not over/underdispersed in models (Kleiber and Zeileis, 2008). Second-order derivations of Akaike's information criterion were used to select models for each prey type which minimised information loss (Barton, 2018), with $\Delta \mathrm{AICc} \leq 2.00$ considered interchangeable (Burnham and Anderson, 2002).

Functional response types were first characterised used binomial generalised linear models and logit links separately for each prey type and water volume (Juliano, 2001; Pritchard et al., 2017). A significantly negative linear coefficient is indicative of a Type II functional response. Second, we fit Rogers' random predator equation to each treatment to account for the non-replacement of prey during the experimental trials (Rogers, 1972):

$$
N_{e}=N_{0}\left(1-\exp \left(a\left(N_{e} h-T\right)\right)\right)
$$

where $N_{e}$ is the number of prey eaten (i.e., number killed), $N_{0}$ is the initial density of prey, $a$ is the attack rate, $h$ is the handling time and $T$ is the total experimental period (hours). The Lambert W function was used to solve the random predator equation (Bolker, 2008). Third, functional response parameters $(a, h)$ were non-parametrically bootstrapped 2000 times to 
generate $95 \%$ confidence intervals across curves for each prey type and water volume. Statistical analyses were performed in R v 3.4.2 (R Development Core Team, 2018).

Approximately $97 \%$ of control prey survived overall, and therefore we did not deem it necessary to adjust experimental feeding rates for background prey mortality. The top model examining feeding rates towards daphnids included water volume, prey supply and their interaction $(\triangle \mathrm{AICc} \leq 1.46)$. Feeding rates related significantly positively with prey supply (GLM: $z=8.10, p<0.001)$, but not water volume (GLM: $z=0.20, p=0.84$ ) or their interaction (GLM: $z=0.96, p=0.34$ ). The top model considering feeding rates upon culicids also included water volume and prey supply, but excluded the interaction term $(\triangle \mathrm{AICc}=2.11)$. Here, feeding rates again related significantly positively to prey supply (GLM: $z=10.53, p<0.001$ ), yet also related significantly negatively to water volume (GLM: $z=4.55, p<0.001$ ). Therefore, the effect of water volume differed between prey types, with a greater negative effect on feeding rates towards surface-dwelling culicids as compared to pelagic daphnids (Figure 1).

Feeding rates towards both prey types always related significantly negatively to prey supplies across water volumes, and thus functional responses were categorised as Type II (Table 1). Attack rates and handling times were significant for the majority of treatment groups (Table 1). Confidence intervals consistently overlapped across prey densities towards daphnids, indicating a lack of significant differences in functional responses among water volume treatments (Figure 2a). By contrast, functional responses towards culicids were influenced to a greater extent by water volume, with significant differences between $20 \mathrm{~mL}$ volumes and all other groups at low-intermediate prey supplies (Figure 2b). This, in turn, reflects greater attack rates and lower handling times under the lowest water volume here (Table 1). 
162 Prey risk differed considerably between prey types across the water volume gradient in the 163 present study, with risk for pelagic daphnid prey less affected by the water volume gradient 164 than the surficial culicid prey. Despite search volumes increasing by several multitudes, and thus prey densities decreasing, daphnid consumption was relatively unaffected and thus higher than expected under higher water volumes. For active pelagic predator-prey pairs, encounter rates are likely less affected by differences in water volume compared to pelagic predators feeding on inactive surface-dwelling prey. In the latter case, prey risk is more variable because the likelihood of being in proximity to surface-dwelling prey increases in shallow waters, whilst prey 'crowding' across densities is more prevalent for daphnid prey. Accordingly, for larval mosquito prey, predatory impact is intensified as water volumes decrease given greater encounter rates at the surface, yet predation is less efficient at greater depths. These findings corroborate Dalal et al. (2019), where the strength of notonectid functional responses towards larval mosquitoes differed according to aquatic search areas. However, despite differences in feeding rates, functional response types were unchanged in the present study, with L. raynerae consistently displaying saturating Type II curves towards both prey types irrespective of water volume. Given Type II functional responses are characterised by high feeding rates at low prey densities (see Dick et al., 2014), L. raynerae is consistently able to capture daphnids and culicids across different water volumes. Nonetheless, attack rates towards mosquitoes were reduced at the highest compared to lowest volume, indicating reduced interaction strengths at low prey densities. Handling times also generally lengthened with increasing water volume for both prey types, causing reduced maximum feeding rates. Previous research has demonstrated large and consistent effects of arena size (i.e. search area) for the determination of foraging rates in laboratory experiments (Uiterwaal et al., 2018), and particularly at low prey densities. 
Here, we further show that search area can alter foraging efficiencies and functional response parameterisation, but that these effects are prey type-dependent.

The present study thus demonstrates the importance of search area for trophic interactions in highly dynamic temporary aquatic ecosystems. Whilst empirical inferences arising from laboratory studies should be treated with necessary caution, applications of comparative functional responses can provide useful insights into environmental context-dependencies in a controlled manner. Alterations to hydrological regimes in future associated with climatic and land use changes may influence interaction strengths differentially among prey species, in turn potentially altering population stabilities and community composition. In particular, deepening of temporary ponds for water storage could reduce the efficacy of specialist predators in controlling vector mosquito populations. Indeed, larval mosquitoes have been observed to be more abundant in deep as compared to shallow ponds in the study area (Dalu pers. comm.). This study further highlights the potential for temporary pond specialist predatory zooplankton to regulate mosquito populations which vector pathogens and parasites, and thus to provide an ecosystem service in terms of public health. If these ecosystems are compromised, such as through being deepened by land owners for water storage purposes, the potential for vector mosquito proliferation may increase. Whilst recent work has also demonstrated strong prey selectivity patterns by predators in temporary ponds (Cuthbert et al., 2019), future studies should also examine the influence of water volume on prey preferences in these systems to further elucidate the implications of search area for trophic interactions concerning vector mosquito populations. Field-based surveys to examine how culicid and daphnid prey abundances shift spatiotemporally according to pond characteristics are also warranted. 
210

This study was funded by the Department for the Economy, Northern Ireland. We thank Choice Maluleke and Consol Kubayi for assisting with fieldwork and experiments. We extend gratitude to Rhodes University for the provision of laboratory facilities. We acknowledge use of infrastructure and equipment provided by the South African Institute for Aquatic Biodiversity (SAIAB) Research Platform and the funding channelled through the National Research Foundation - SAIAB Institutional Support system. This study was partly funded by the National Research Foundation - South African Research Chairs Initiative of the Department of Science and Technology (Inland Fisheries and Freshwater Ecology, Grant No. 110507) and National Research Foundation Thuthuka Grant (No. 117700).

\section{References}

Barton, K., 2018. MuMIn: Multi-Model Inference. R package version 1.42.1.

Bolker, B.M., 2008. Emdbook: Ecological Models and Data in R. Princeton University Press, New Jersey.

Burnham, K.P., Anderson, D.R., 2002. Model Selection and Multi-model Inference: A Practical Information-Theoretic Approach. Springer, New York.

Cuthbert, R.N., Dickey, J.W.E., McMorrow, C., Laverty, C., Dick, J.T.A., 2018. Resistance is futile: lack of predator switching and a preference for native prey predict the success of an invasive prey species. R. Soc. Open Sci. 5, 180339.

Cuthbert, R.N., Dalu, T., Wasserman, R.J., Weyl, O.L.F., Fronean, P.W.., Callaghan, A., Dick, J.T.A. 2019. Lack of prey switching and strong preference for mosquito prey by a temporary pond specialist predator. Ecol. Entomol., in press. 
Dalal, A., Cuthbert, R.N., Dick, J.T.A., Gupta, S., 2019. Water depth-dependent notonectid predatory impacts across larval mosquito ontogeny. Pest Manage. Sci. 75, 2610-2617.

Dalu, T., Wasserman, R.J., Dalu, M.T., 2017. Agricultural intensification and drought frequency increases may have landscape-level consequences for ephemeral ecosystems. Glob. Change Biol. 23, 983-985.

Dick, J.T.A., Alexander, M.E., Jeschke, J.M., Ricciardi, A., MacIsaac, H.J., Robinson, T.B., Kumschick, S., Weyl, O.L.F., Dunn, A.M., Hatcher, M.J., Paterson, R.A., Farnsworth, K.D., Richardson, D.M., 2014. Advancing impact prediction and hypothesis testing in invasion ecology using a comparative functional response approach. Biol. Invasions 16, $735-753$.

Holling, C.S., 1959. Some characteristics of simple types of predation and parasitism. Can. Entomol. 91, 385-398.

Juliano, S.A., 2001. Nonlinear curve fitting: predation and functional response curves. Design and Analysis of Ecological Experiments (ed. by Scheiner, S.M., Gurvitch, J.), pp. 178196. Oxford University Press, Oxford.

Kleiber, C., Zeileis, A., 2008. Applied Econometrics with R. Springer-Verlag, New York.

Laverty, C., Dick, J.T.A., Alexander, M.E., Lucy, F.E., 2015. Differential ecological impacts of invader and native predatory freshwater amphipods under environmental change are revealed by comparative functional responses. Biol. Invasions 17, 1761-1770.

McCann, K., Hastings, A., Huxel, G.R., 1998. Weak trophic interactions and the balance of nature. Nature 395, 794-798. 
Pritchard, D.W., Paterson, R.A., Bovy, H.C., Barrios-O’Neill, D., 2017. FRAIR: an R package for fitting and comparing con- sumer functional responses. Methods Ecol. Evol. 8, $1528-1534$.

R Development Core Team, 2018. R: A Language and Environment for Statistical Computing. Vienna.

Rogers, D., 1972. Random search and insect population models. J. Anim. Ecol. 41, 369-383.

Uiterwaal, S.F., DeLong, J.P. 2018. Multiple factors, including arena size, shape the functional responses of ladybird beetles. J. Appl. Ecol. 55, 2429-2438.

Vázquez, D.P., Ramos-Jiliberto, R., Urbani, P., Valdovinos, F.S., 2015. A conceptual framework for studying the strength of plant-animal mutualistic interactions. Ecol. Lett. $18,385-400$.

Wasserman, R.J., Weston, M., Weyl, O.L.F., Froneman, P.W., Welch, R.J., Vink, T.J.F., Dalu, T., 2018. Sacrificial males: the potential role of copulation and predation in contributing to copepod sex-skewed ratios. Oikos $127,970-980$. 
group by Lovenula raynere, as well as associated $p$-values. Functional response parameters are standardised hourly towards each prey group.

\begin{tabular}{|l|l|l|l|l|l|}
\hline Prey & Volume & Density range & Linear & Attack rate, & Handling \\
& $(\mathrm{mL})$ & $\left(\right.$ prey $\left.\mathrm{mL}^{-1}\right)$ & coefficient, $p$ - & $p$-value & time, $p$-value \\
\hline Daphnid & 20 & $0.1-1.6$ & $-0.06,<0.001$ & $0.15,<0.001$ & $0.69,<0.001$ \\
\hline Daphnid & 40 & $0.05-0.80$ & $-0.08,<0.001$ & $0.24,<0.001$ & $1.11,<0.001$ \\
\hline Daphnid & 60 & $0.03-0.53$ & $-0.05,<0.001$ & $0.12,<0.001$ & $0.77,<0.001$ \\
\hline Daphnid & 80 & $0.03-0.40$ & $-0.07,<0.001$ & $0.16,<0.001$ & $1.14,<0.001$ \\
\hline Daphnid & 100 & $0.02-0.32$ & $-0.08,<0.001$ & $0.21,<0.001$ & $1.26,<0.001$ \\
\hline Culicid & 20 & $0.1-1.6$ & $-0.09,<0.001$ & $0.77,<0.001$ & $0.31,<0.001$ \\
\hline Culicid & 40 & $0.05-0.80$ & $-0.05,<0.001$ & $0.40,0.001$ & $0.40,<0.001$ \\
\hline Culicid & 60 & $0.03-0.53$ & $-0.05,<0.001$ & $0.29,<0.001$ & $0.38,<0.001$ \\
\hline Culicid & 80 & $0.03-0.40$ & $-0.05,<0.001$ & $0.67,0.07$ & $0.72,<0.001$ \\
\hline Culicid & 100 & $0.02-0.32$ & $-0.05,<0.001$ & $0.21,0.002$ & $0.48,<0.001$ \\
\hline
\end{tabular}

277 


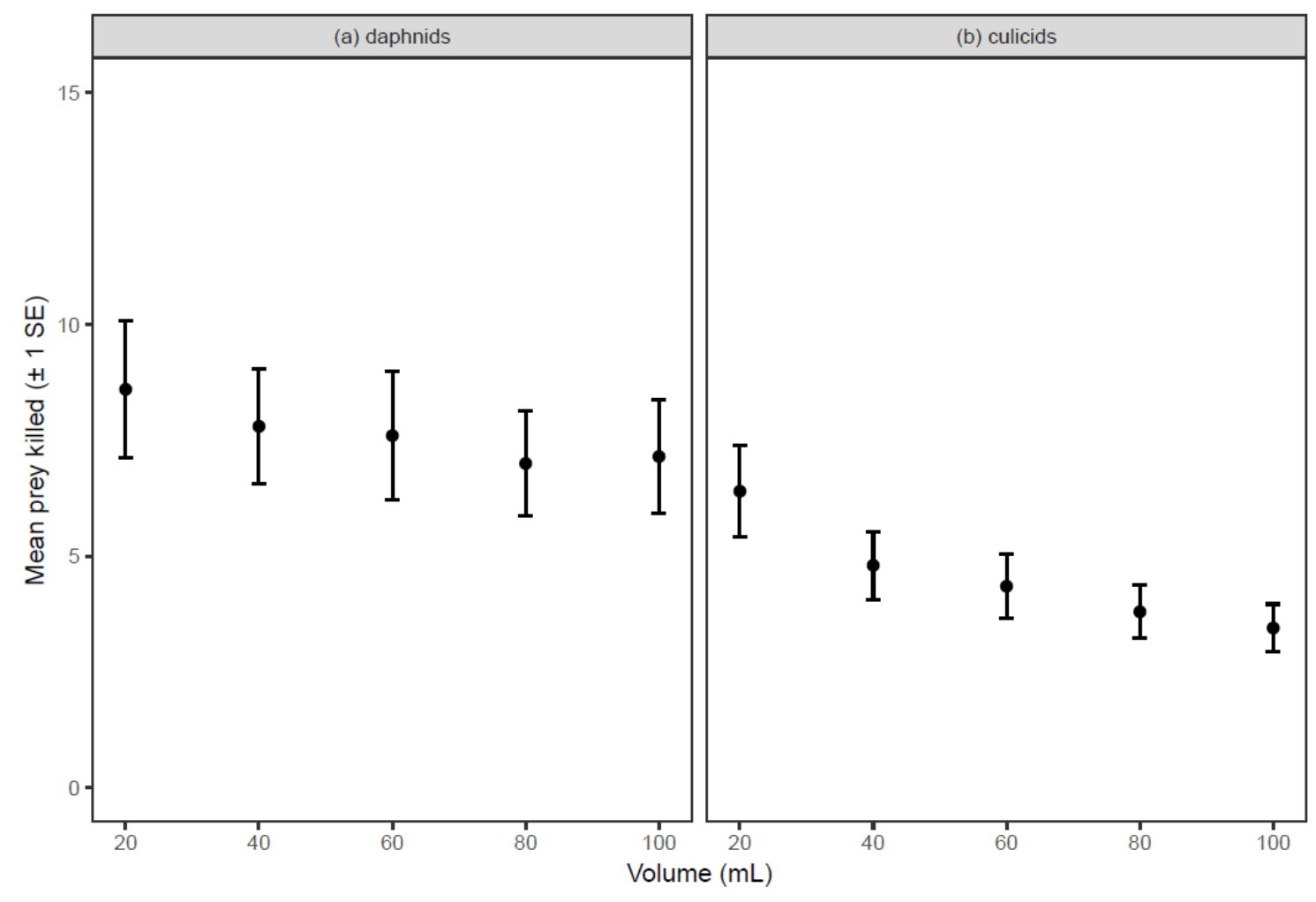

283

284 Figure 1. Mean ( $\pm 1 \mathrm{SE}$ ) feeding rates of Lovenula raynerae towards daphnid (Daphnia 285 longispina, a) and larval culicid (Culex pipiens, b) prey across water volume treatments, 286 irrespective of prey density and feeding duration.

287

288

289

290

291

292

293 


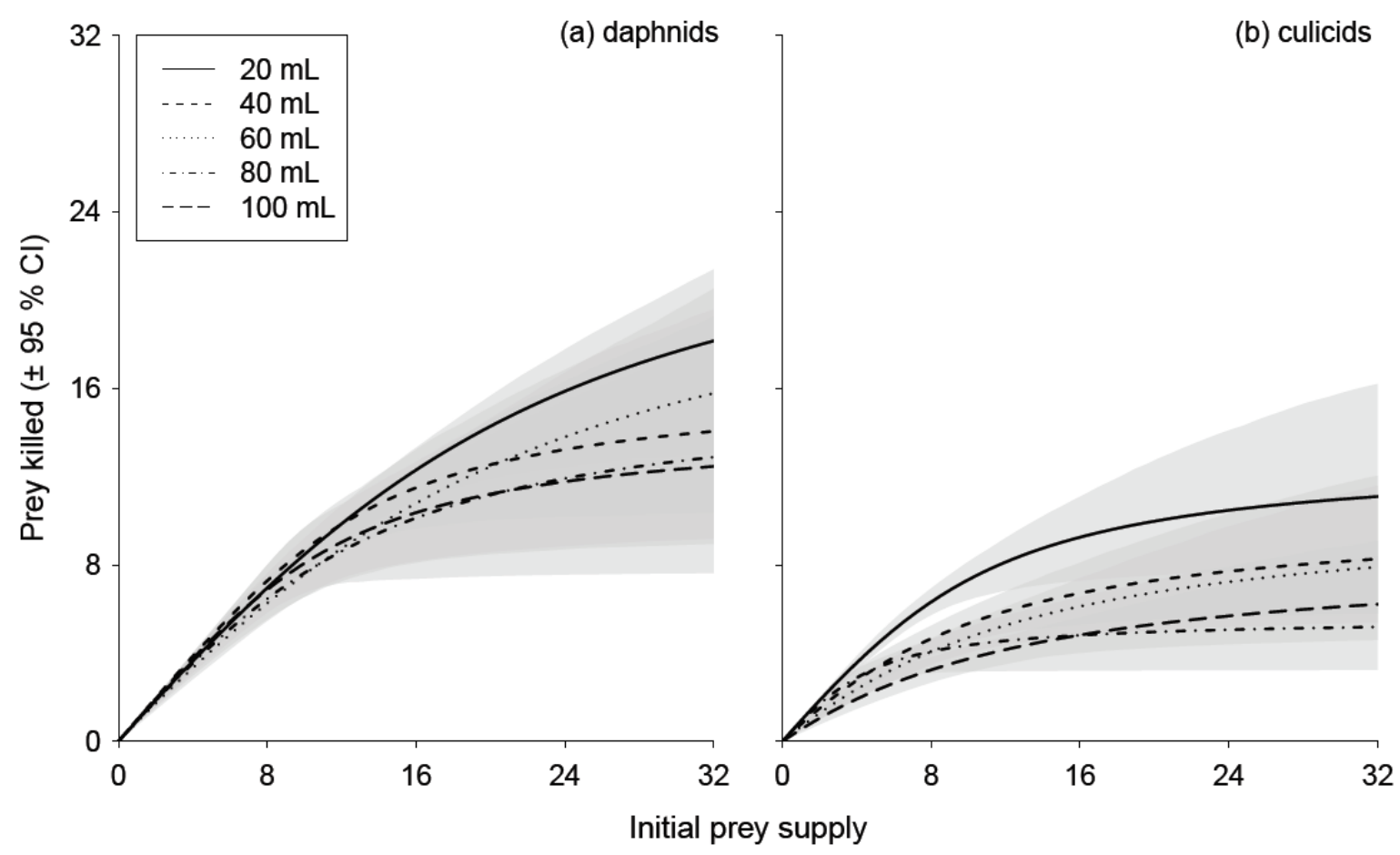

296

297 Figure 2. Type II functional response curves of Lovenula raynerae towards daphnid

298 (Daphnia longispina, a) and larval culicid (Culex pipiens, b) prey under different water

299 volume treatments, irrespective of experimental duration. Shaded areas are bootstrapped 95

$300 \%$ confidence intervals. 